\title{
Emergency percutaneous coronary interventions for unprotected left main stenoses: immediate and long term follow up
}

\author{
B R G Brueren, J M P G Ernst, M J Suttorp, J M ten Berg, B J W M Rensing, E G Mast, E T Bal, A J Six, \\ H W M Plokker
}

Heart 2004;90:1067-1068. doi: 10.1136/hrt.2003.021378

\begin{abstract}
A cute occlusion of the unprotected left main coronary artery (LMCA) is fatal in most cases. The life of the patient can be saved by the rapid reperfusion of the occluded LMCA by means of catheter intervention. However, percutaneous coronary interventions (PCI) of LMCA are discouraged by most guidelines. We describe 35 patients who underwent emergency PCI of the unprotected LMCA.

\section{METHODS}

Emergency PCI of the unprotected LMCA was performed in 35 cases, representing $0.2 \%$ of the 17683 patients who underwent PCI at our centre between January 1990 and July 2001. Twenty six of the study patients $(74.3 \%)$ were being treated in the setting of acute myocardial infarction (AMI). In the nine other patients $(25.7 \%)$ the procedure was performed as an emergency treatment for dissection that occurred during coronary angiography. Patient characteristics and angiographic data are shown in table 1.

The magnitude of STT elevation in lead AVR is also shown in table 1. Twenty four patients (68.6\%) had ST segment elevation in lead AVR. Patients with an LMCA occlusion due to complicated coronary angiography did not have a pretreatment ECG.
\end{abstract}

Table 1 Characteristics and angiographic data of 35 patients undergoing emergency $\mathrm{PCl}$ of the LMCA

\begin{tabular}{lc}
\hline Total PCI ( $\mathbf{n}=17683)$ & $\begin{array}{c}\text { Number of } \\
\text { patients }(\%)\end{array}$ \\
\hline Urgent PCl of the unprotected LMCA & $26(0.15 \%)$ \\
AMI & $9(0.05 \%)$ \\
Complicated CAG & $67.1(12.3)$ \\
Mean (SD) age (years) & $10(29 \%)$ \\
Female & $30(85.7 \%)$ \\
History of CAD & $8(22.9 \%)$ \\
STT elevation in lead AVR & $7(20.0 \%)$ \\
$+0.5 \mathrm{mV}$ & $1(2.9 \%)$ \\
$+1.0 \mathrm{mV}$ & $8(22.9 \%)$ \\
$+1.5 \mathrm{mV}$ & $9(25.7 \%)$ \\
$+2.0 \mathrm{mV}$ & $2(5.7 \%)$ \\
Acute ECG not available & $104(126) \mathrm{mins}$ \\
No STT elevation & \\
Mean (SD) duration of ischaemia & $25 / 10$ \\
Dominance of RCA & $6(17.1 \%)$ \\
Yes/no & $20(57.1 \%)$ \\
RCA occluded & $17(48.6 \%)$ \\
Occlusion of LMCA & \\
Calcification &
\end{tabular}

$A M I$, acute myocardial infarction; $C A D$, coronary artery disease; $L M C A$, left main coronary artery; $\mathrm{PCl}$, percutaneous coronary intervention; $\mathrm{RCA}$, right coronary artery.

\section{RESULTS}

Twenty patients (57.1\%) had a total occlusion of the LMCA. A stent was used in 25 patients $(71.4 \%)$; in one case a cutting balloon was used and in one further case a rotablator was applied. In 20 patients (57.1\%) an intra-aortic balloon pump was used. Cardiopulmonary resuscitation was needed in seven patients $(20 \%)$. Six patients $(17.1 \%)$ were transferred to the operating room for emergency coronary bypass surgery immediately after orthograde flow in the LMCA was obtained.

Median follow up was 722 days (interquartile range 01847 days). One year follow up reveals a cumulative mortality of $41 \%$. The 15 patients who died did so under the following circumstances. Seven patients $(58.3 \%)$ died within 10 minutes of arrival in the catheterisation laboratory because of haemodynamics that could not be corrected, in four of these patients attempts to open the occluded LMCA had not been successful, and three other patients died in cardiogenic shock despite recanalisation. Two patients survived the PCI procedure but died within 24 hours from cardiac failure. The remaining three patients died because of aspiration pneumonia on day 3 , a repeated arrest on day 8 , and one patient had a cerebrovascular accident as a complication of surgery for groin bleeding. None of the 20/35 (59\%) early survivors died during the long term follow up. Additional revascularisations occurred in two of these 20 patients (10\%), one patient underwent coronary artery bypass grafting (CABG) after 31 months, the other $\mathrm{CABG}$ and mitral valve surgery after 59 months. The Kaplan-Meier survival curve is shown in fig 1.

\section{DISCUSSION}

Generally, PCI is a safe and effective treatment for most significant coronary stenoses. An exception is PCI of the LMCA, which is not practised routinely, as balloon induced dissection of the LMCA may result in an immediately life threatening condition. In contrast, CABG is a safe alternative. However, emergency CABG is logistically not always feasible; even when the operating theatre and the surgical team are available, the preparations for cardiac surgery may last longer than the haemodynamic circumstances of the patient allows. In contrast, catheter interventions do not require significant preparations. Once the patient has arrived in the catheterisation laboratory, procedures may be carried out within minutes. Emergency catheter interventions may result in an

Abbreviations: $A M I$, acute myocardial infarction; $C A B G$, coronary artery bypass graffing; LMCA, left main coronary artery; $\mathrm{PCl}$, percutaneous coronary intervention 


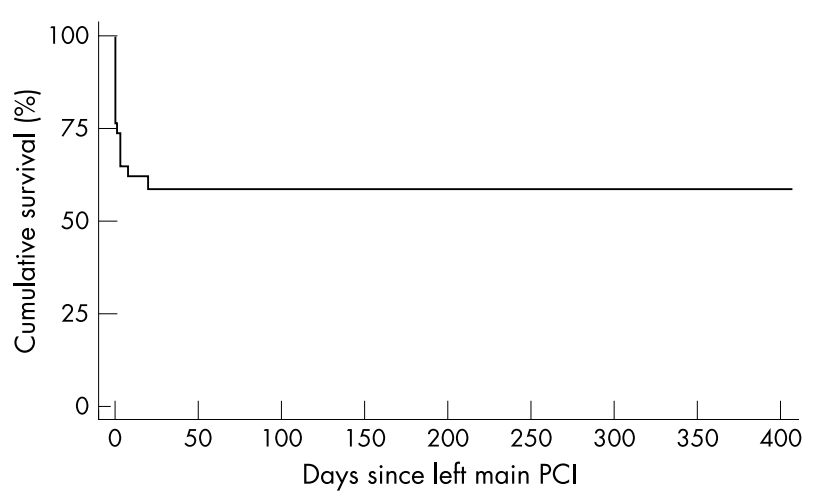

Figure 1 Kaplan-Meier survival curve: cardiac death.

immediate restoration of haemodynamics, thus potentially saving lives.

Since PCI has been accepted as a standard treatment for AMI, ${ }^{12}$ experience with emergency PCI for the unprotected LMCA is growing..$^{3-5}$ Most publications on this matter concern small subgroups from larger cohorts of patients undergoing PCI. De Luca (from the Zylstra group) so far describes the largest group ${ }^{5} ; 24$ patients underwent PCI for LMCA obstruction in the setting of AMI. Fourteen of these patients $(58 \%)$ died either in the catheterisation laboratory or during the initial hospitalisation.

In our study the time delay between onset of symptoms and time of restoration of coronary blood flow appears to be the only strong predictor of mortality in a univariate analysis. Each quarter of delay results in a $30 \%$ increase of the risk of death.

Our study concerns a group of 35 patients with LMCA stenosis or occlusion, presenting at our high volume intervention centre during a 10 year time period. It has never been a policy at our centre to perform PCI of the LMCA routinely, but the immediately life threatening condition of acute closure of the LMCA forced us to carry out this life saving procedure. We strongly believe that scarcely any of these 35 patients would have survived without the catheter intervention. Applicable literature on the prognosis of untreated acute LMCA obstruction is lacking but in all studies on PCI under this condition, treatment failure results in low survival rates.

Fifteen patients died either during the procedure or within the first week thereafter. Survivors had an excellent prognosis with not one single patient dying during the 10 year follow up period. This remarkable finding is consistent with the only larger study published so far. ${ }^{5}$ Not surprisingly, a significant proportion $(10 \%)$ of the survivors underwent additional revascularisations at a later stage, either by PCI or CABG.

In conclusion, the lives of $59 \%$ of the study population were saved by the procedure.

\section{Authors' affiliations}

B R G Brueren, Department of Cardiology, Catharina Ziekenhuis, Eindhoven, The Netherlands

J M P G Ernst, M J Suttorp, J M ten Berg, B J W M Rensing, E G Mast, E T Bal, A J Six, H W M Plokker, Department of Cardiology, St Antonius Hospital, Nieuwegein, The Netherlands

Correspondence to: B R G Brueren, Department of Cardiology, Catharina Ziekenhuis, Michelangelolaan 2, Postbus 1350, 5602 ZA, The Netherlands; guus.brueren@cze.nl

Accepted 2 December 2003

\section{REFERENCES}

1 Grines CL, Browne KF, Marco J, et al. A comparison of immediate angioplasty with thrombolytic therapy for acute myocardial infarction. N Engl J Med 1993;328:673-9

2 Andersen HR, Nielsen TT, Rasmussen K, et al. A comparison of coronary angioplasty with fibrinolytic therapy in acute myocardial infarction. N Engl J Med 2003;349:733-42.

3 Spiecker M, Erbel R, Rupprecht H-J, et al. Emergency angioplasty of totally occluded left main coronary artery in acute myocardial infarction and unstable angina pectoris- Institutional experience and literature review. Eur Heart J 1994; 15:602-7.

4 Tan WA, Tamai H, Park S-J, et al. Long-term clinical outcomes after unprotected left main trunk percutaneous revascularization in 279 patients. Circulation 2001; 104:1609-14.

5 De Luca G, Suryapranata $\mathrm{H}$, Thomas $\mathrm{K}$, et al. Outcome in patients treated with primary angioplasty for acute myocardial infarction due to left main coronary artery occlusion. Am J Cardiol 2003;91:235-7.

\section{ELECTRONIC PAGES}

\section{Heart Online case reports: www.heartjnl.com}

$\mathrm{T}$

he follow electronic only articles are published in conjunction with this issue of Heart.

\section{Atrioventricular nodal re-entrant tachycardia in a patient with Ebstein anomaly}

G Mönnig, K Wasmer, L Eckardt

The first case of successful slow pathway modulation is reported in a patient with Ebstein anomaly and recurrent atrioventricular nodal re-entrant tachycardia. Typical signals were recorded during electrophysiological study at the slow pathway region between the His bundle and the coronary sinus where ablation was performed successfully. Thus, slow pathway modulation seems to be a safe procedure even in selected patients with Ebstein anomaly.

(Heart 2004;90:e58) www.heartjnl.com/cgi/content/full/90/ $9 / \mathrm{e} 58$
Late gadolinium enhanced cardiovascular magnetic resonance in Becker muscular dystrophy A Varghese, D J Pennell

Becker muscular dystrophy is a rare cause of dilated cardiomyopathy. A case of Becker muscular dystrophy is reviewed in which cardiovascular magnetic resonance showed previously unreported findings of extensive midmyocardial late gadolinium enhancement. Similar detection of late gadolinium enhancement in conjunction with other uses of cardiovascular magnetic resonance may contribute significantly to the diagnosis and management of patients with this unusual and important diagnosis.

(Heart 2004;90:e59) www.heartjnl.com/cgi/content/full/90/ $9 / \mathrm{e} 59$ 